Article

\title{
Comparative Study of Metal Substrates for Improved Carbonization of Electrospun PAN Nanofibers
}

\author{
Jan Lukas Storck ${ }^{1} \mathbb{D}$, Martin Wortmann ${ }^{2} \mathbb{D}$, Bennet Brockhagen ${ }^{1}$, Natalie Frese ${ }^{2}$, Elise Diestelhorst ${ }^{1}$, \\ Timo Grothe ${ }^{1}$ D, Christian Hellert ${ }^{1}$ and Andrea Ehrmann ${ }^{1, * \mathbb{D}}$
}

1 Faculty of Engineering and Mathematics, Bielefeld University of Applied Sciences, 33619 Bielefeld, Germany; jan_lukas.storck@fh-bielefeld.de (J.L.S.); bennet.brockhagen@fh-bielefeld.de (B.B.); elise.diestelhorst@fh-bielefeld.de (E.D.); timo.grothe@fh-bielefeld.de (T.G.); christian.hellert@fh-bielefeld.de (C.H.)

2 Faculty of Physics, Bielefeld University, 33615 Bielefeld, Germany; martin.wortmann@fh-bielefeld.de (M.W.); nfrese@uni-bielefeld.de (N.F.)

* Correspondence: andrea.ehrmann@fh-bielefeld.de

\section{check for}

Citation: Storck, J.L.; Wortmann, M.; Brockhagen, B.; Frese, N.;

Diestelhorst, E.; Grothe, T.; Hellert, C.; Ehrmann, A. Comparative Study of Metal Substrates for Improved Carbonization of Electrospun PAN Nanofibers. Polymers 2022, 14, 721. https://doi.org/10.3390/ polym14040721

Academic Editor: Andreea-Teodora Iacob

Received: 24 January 2022

Accepted: 11 February 2022

Published: 13 February 2022

Publisher's Note: MDPI stays neutral with regard to jurisdictional claims in published maps and institutional affiliations.

Copyright: (C) 2022 by the authors. Licensee MDPI, Basel, Switzerland. This article is an open access article distributed under the terms and conditions of the Creative Commons Attribution (CC BY) license (https:// creativecommons.org/licenses/by/ $4.0 /)$.

\begin{abstract}
Carbon nanofibers are used for a broad range of applications, from nano-composites to energy storage devices. They are typically produced from electrospun poly(acrylonitrile) nanofibers by thermal stabilization and carbonization. The nanofiber mats are usually placed freely movable in an oven, which leads to relaxation of internal stress within the nanofibers, making them thicker and shorter. To preserve their pristine morphology they can be mechanically fixated, which may cause the nanofibers to break. In a previous study, we demonstrated that sandwiching the nanofiber mats between metal sheets retained their morphology during stabilization and incipient carbonization at $500{ }^{\circ} \mathrm{C}$. Here, we present a comparative study of stainless steel, titanium, copper and silicon substrate sandwiches at carbonization temperatures of $500{ }^{\circ} \mathrm{C}, 800{ }^{\circ} \mathrm{C}$ and $1200{ }^{\circ} \mathrm{C}$. Helium ion microscopy revealed that all metals mostly eliminated nanofiber deformation, whereas silicone achieved the best results in this regard. The highest temperatures for which the metals were shown to be applicable were $500{ }^{\circ} \mathrm{C}$ for silicon, $800{ }^{\circ} \mathrm{C}$ for stainless steel and copper, and $1200{ }^{\circ} \mathrm{C}$ for titanium. Fourier transform infrared and Raman spectroscopy revealed a higher degree of carbonization and increased crystallinity for higher temperatures, which was shown to depend on the substrate material.
\end{abstract}

Keywords: electrospinning; poly(acrylonitrile); stabilization; carbonization; metallic substrates; shrinkage; nanofiber morphology

\section{Introduction}

Poly(acrylonitrile) (PAN) nanofibers are typically produced either by needle-based or by needleless electrospinning methods (cf. Figure 1A) and are a common precursor for carbon nanofibers (CNF) [1,2]. Due to their outstanding electrical and mechanical properties, CNF are particularly promising for nano composites [3-5]. In particular, freestanding CNF mats with sufficient mechanical strength that can be used without a substrate have attracted considerable attention [6-8].

For the production of CNF, pristine PAN nanofibers are usually first oxidatively stabilized below $300{ }^{\circ} \mathrm{C}$ and then carbonized above $500{ }^{\circ} \mathrm{C}$ in an inert atmosphere. Much research has focused on the optimization of process parameters such as heating rate and terminal temperature [9-11]. Higher temperatures generally result in a higher degree of carbonization and crystallinity, thus improving stability and electrochemical properties [12,13]. The heating rate, especially during stabilization, plays a crucial role in retaining the original nanofiber morphology $[2,12,13]$.

Another aspect, not related to thermal but to mechanical treatment, is the possible fixation or even stretching of pristine nanofibers during stabilization and carbonization. The thermally induced relaxation of internal stress, as introduced by extreme polymer 
chain elongation during electrospinning, usually results in undesirable deformation and contraction of the CNF, observed both macroscopically and on a nanometer scale [14-16]. This process can be counteracted by applying a force during the temperature treatment, either by fixation of the pristine nanofiber mat or by stretching of aligned nanofiber bundles [17-19]. While the latter method has been shown to work well in the literature, the former, although much simpler, can cause the nanofiber mat to break.
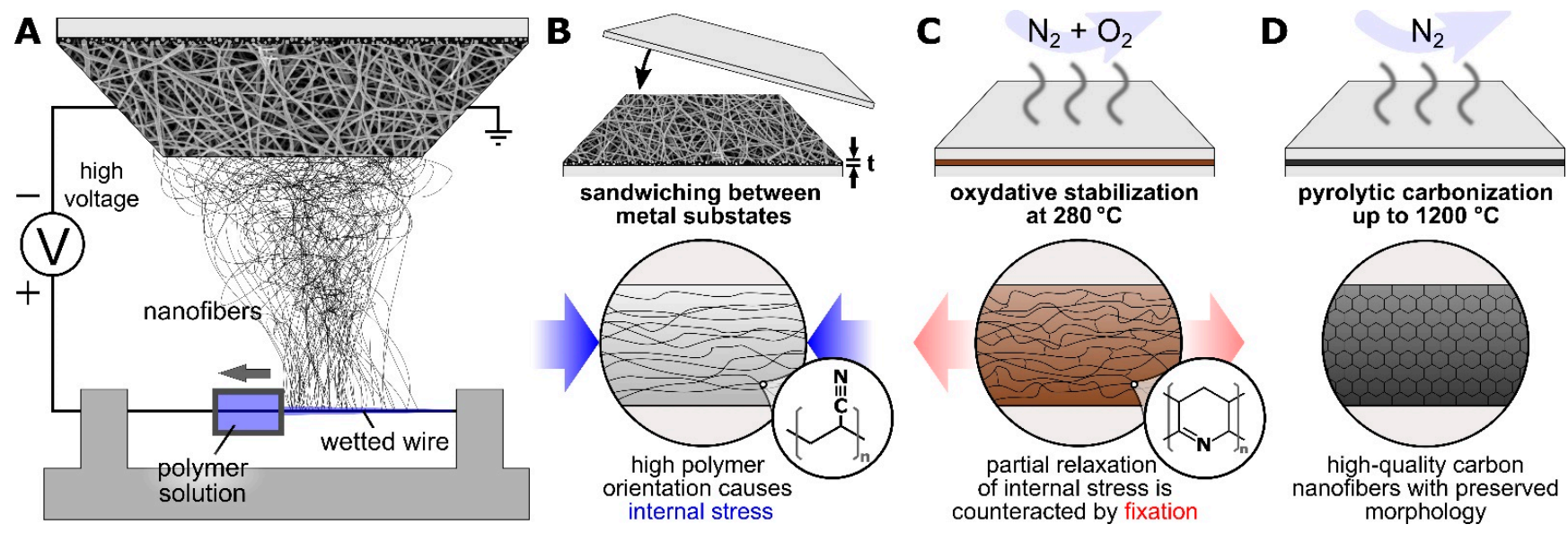

Figure 1. Schematic illustration of (A) wire-based electrospinning, (B) sample preparation, (C) stabilization and (D) carbonization using different metal substrates.

In an earlier study, we demonstrated that metallic substrates are a simple and efficient way to retain both the macroscopic dimensions of PAN-based CNF mats and the nanoscopic fiber morphology during the thermo-oxidative stabilization. For this, the pristine PAN nanofibers are spun directly onto aluminum foil or other rigid metal substrates. The adhesion of the nanofibers to the substrate enables a uniform stress distribution preventing fiber deformation without breaking [20-22]. In our most recent study, we showed that stabilization and incipient carbonization could be improved by sandwiching the PAN nanofiber mats between aluminum or stainless steel sheets [23]. Aluminum, however, cannot be used for higher temperatures and is thus not suitable for high-temperature carbonization.

In this study, we compare different substrate materials that form sandwiches with the nanofiber mats (cf. Figure 1B) for incipient carbonization at $500{ }^{\circ} \mathrm{C}$ and, as far as possible with the chosen substrates, higher temperatures of up to $800^{\circ} \mathrm{C}$ and $1200{ }^{\circ} \mathrm{C}$ (cf. Figure $1 \mathrm{C}, \mathrm{D})$, showing that different substrate materials are optimal for different carbonization temperatures. In this regard carbonization at $800{ }^{\circ} \mathrm{C}$ with copper substrates results in an ideal compromise of intact nanofibers and crystallinity, while titanium substrates enabled carbonization at $1200{ }^{\circ} \mathrm{C}$.

\section{Materials and Methods}

PAN nanofiber mats were produced in a needleless electrospinning instrument Nanospider Lab (Elmarco, Liberec, Czech Republic). The spinning solution was prepared from $16 \%$ PAN (X-PAN, from Dralon, Dormagen, Germany), dissolved in dimethyl sulfoxide (DMSO, min. 99.9\%; S3 Chemicals, Bad Oeynhausen, Germany), by stirring for $2 \mathrm{~h}$ at ambient temperature.

The spinning parameters were as follows: high voltage $80 \mathrm{kV}$, resulting current $\sim 0.1 \mathrm{~mA}$, nozzle diameter $0.9 \mathrm{~mm}$, electrode-substrate distance $240 \mathrm{~mm}$, carriage speed $100 \mathrm{~mm} / \mathrm{s}$, substrate speed $0 \mathrm{~mm} / \mathrm{min}$, relative humidity $32 \%$, temperature in the spinning chamber $22{ }^{\circ} \mathrm{C}$, and spinning duration $30 \mathrm{~min}$. These parameters are identical to those chosen in the previous studies [21-23].

For comparison with the previous study [23], a stainless steel 1.4301 V2a sheet (thickness $500 \mu \mathrm{m}$; Stahlog GmbH, Hörselberg-Hainich, Germany) was again used to prepare substrate-nanofibers-substrate sandwiches for stabilization and subsequent carbonization. In addition, three substrates (used in [22] as single-sided supports, i.e., without capping 
the nanofiber mats by a second substrate) were investigated as sandwiches: copper foil, thickness $100 \mu \mathrm{m}$ (Blechmaennle-de, Rottenburg, Germany); a titanium sheet, thickness $100 \mu \mathrm{m}$ (Evek GmbH, Mühlheim an der Ruhr, Germany); and a silicon (100) wafer with an oxidized surface, thickness $525 \mu \mathrm{m}$ (Science Service $\mathrm{GmbH}$, Munich, Germany).

For stabilization, a muffle oven B150 (Nabertherm, Lilienthal, Germany) was used to keep the samples at a temperature of $280^{\circ} \mathrm{C}$ for $1 \mathrm{~h}$, approached with a heating rate of $0.25 \mathrm{~K} / \mathrm{min}$. Carbonization was carried out in a tube furnace CTF 12/TZF 12 (Carbolite Gero Ltd., Sheffield, UK) at $500{ }^{\circ} \mathrm{C}, 800{ }^{\circ} \mathrm{C}$ or $1200{ }^{\circ} \mathrm{C}$ for $1 \mathrm{~h}$, all temperatures approached with heating rates of $10 \mathrm{~K} / \mathrm{min}$ in a nitrogen gas flow of $100 \mathrm{~mL} / \mathrm{min}$ (STP). Heating rates and stabilization temperature correspond to the values from our previous studies [21-23].

To examine the morphology of the nanofibers after stabilization and carbonization, a helium ion microscope (HIM) Orion Plus (Carl Zeiss, Jena, Germany) was used with $35.9 \mathrm{kV}$ acceleration voltage. The spot control was defined as 6.5 , resulting in a beam current of 0.6-0.7 pA. An electron flood gun was used to avoid charging effects during secondary electron detection.

ImageJ (version 1.53e, 2021, National Institutes of Health, Bethesda, MD, USA) was used to measure nanofiber diameters (from HIM images with field of view $8 \mu \mathrm{m}$, taking 100 measurements per images) and to count broken nanofiber ends (from HIM images with field of view $30 \mu \mathrm{m}$, using the Multi-point counting function).

For the investigation of the carbonization process, a Fourier-transform infrared (FTIR) spectrometer Excalibur 3100 (Varian Inc., Palo Alto, CA, USA) in attenuated total reflection mode (ATR-FTIR) was used in the wavenumber range from $4000-700 \mathrm{~cm}^{-1}$. For Raman investigations, a LabRAM Aramis spectrometer (HORIBA Europe, Oberursel, Germany) with a cooled CCD detector and a helium-neon laser at $633 \mathrm{~nm}$ was used in backscattering mode. The $I_{D} / I_{G}$ ratio was calculated from the peak amplitudes.

Sample thickness measurements were performed by a Fischerscope MMS PC2 with EGAB 1.3 probe (Helmut Fischer GmbH, Sindelfingen, Germany).

\section{Results and Discussion}

For an overview of the nanofiber morphologies after stabilization and carbonization at different temperatures, Figure 2 depicts HIM images of all nanofiber mats. The open positions indicate samples, which were vanished after carbonization at the respective temperatures. Generally, all images show apparently intact nanofiber mats with random nanofiber distribution, as it is expected from needleless electrospinning with stationary substrates. The beads which are visible in a few images often occur when PAN is electrospun from DMSO, varying with small changes in the relative humidity in the spinning chamber. However, the diameter distributions vary slightly between the different substrates, as Figure 3A shows.

Comparing the diameters, no significant differences are visible. The values measured here are slightly smaller than those reported in [23] for incipient carbonization at $500{ }^{\circ} \mathrm{C}$ in aluminum sandwiches. There is neither a trend towards larger diameters for carbonized nanofibers, as could be expected if the nanofibers had shrunken, nor a trend towards smaller diameters after thermal treatment due to a significant mass loss. The diameter distributions, as indicated by the error bars, do not differ significantly, either. This result shows that all substrate materials used are well suited to preserve the nanoscopic fiber morphology in terms of diameter, topography and homogeneity during heat treatment.

The fixation of the nanofibers to the substrate surface generates mechanical tensions during heat treatment, which eventually oppose the deformation. It has already been shown $[22,23]$ that this can lead to breakage of individual CNFs. Figure 3B thus shows the number of broken nanofiber ends, as counted in the HIM images shown in Figure 2. In a perfect CNF mat, nearly no broken nanofiber ends are visible since electrospun nanofibers typically have lengths in the range up to millimeters, making the probability of seeing fiber ends in images of only $30 \mu \mathrm{m}$ edge length (cf. Figure 2) very low. 

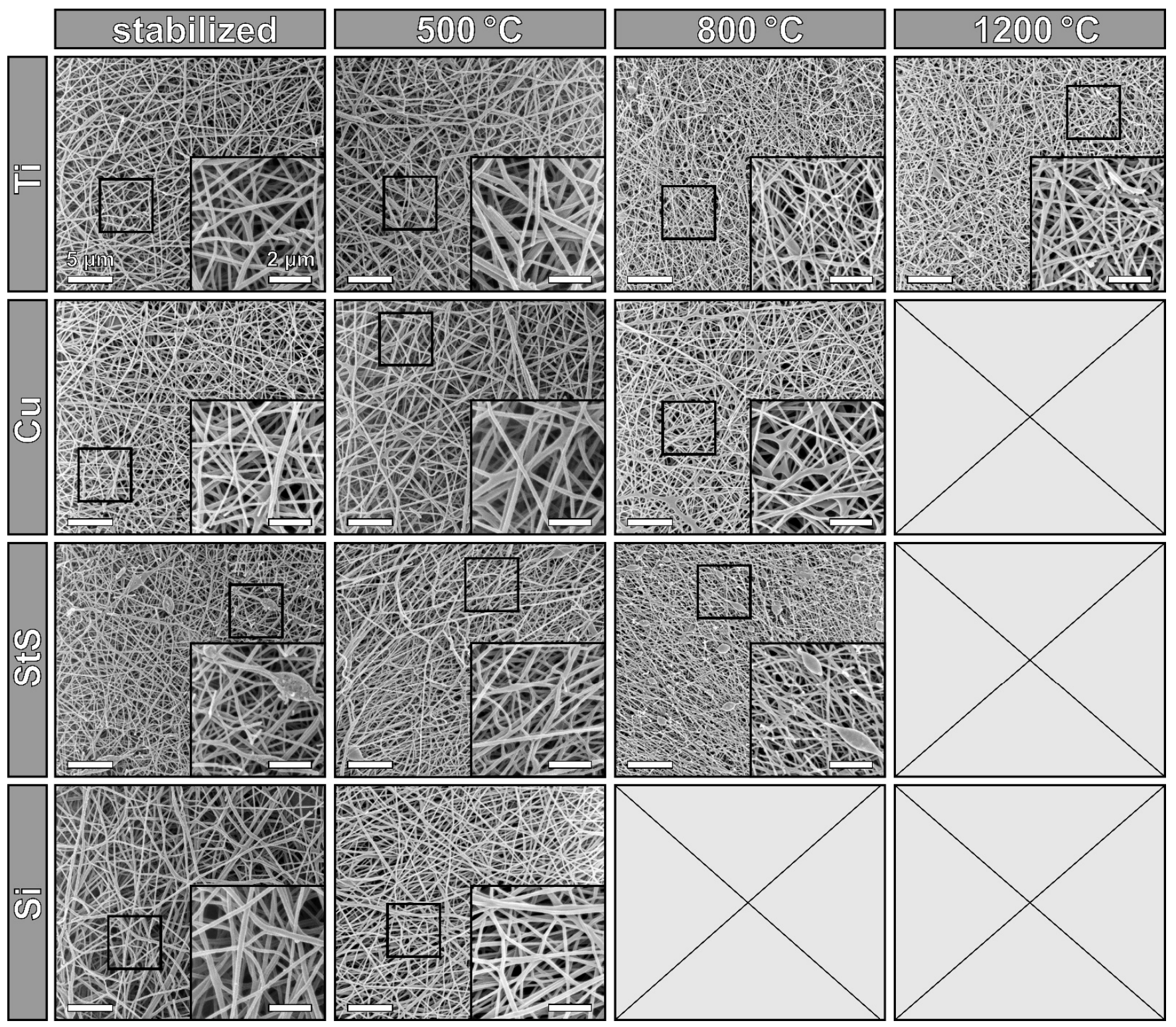

Figure 2. HIM images of CNF mats, stabilized and carbonized at different temperatures, sandwiched between titanium $(\mathrm{Ti})$, copper $(\mathrm{Cu})$, stainless steel $(\mathrm{StS})$ sheets and silicon $(\mathrm{Si})$ wafers, respectively. Scale bars define $5 \mu \mathrm{m}$ in the large images and $2 \mu \mathrm{m}$ in the insets.

There is no general trend visible regarding the increase or decrease of the number of broken nanofibers with increasing treatment temperature. For the titanium substrates, the broken ends clearly increase with higher carbonization temperatures; however, the opposite trend is visible for the copper substrates. This is presumably due to the statistical variance between different sample regions in connection with the limited size of the HIM images, thus no generalizing conclusions can be drawn here [24].

Overall, the highest numbers of broken ends are reached with the stainless steel substrate, while the Si wafer seems to be, in this regard, ideally suited for stabilization and incipient carbonization at $500{ }^{\circ} \mathrm{C}$. 

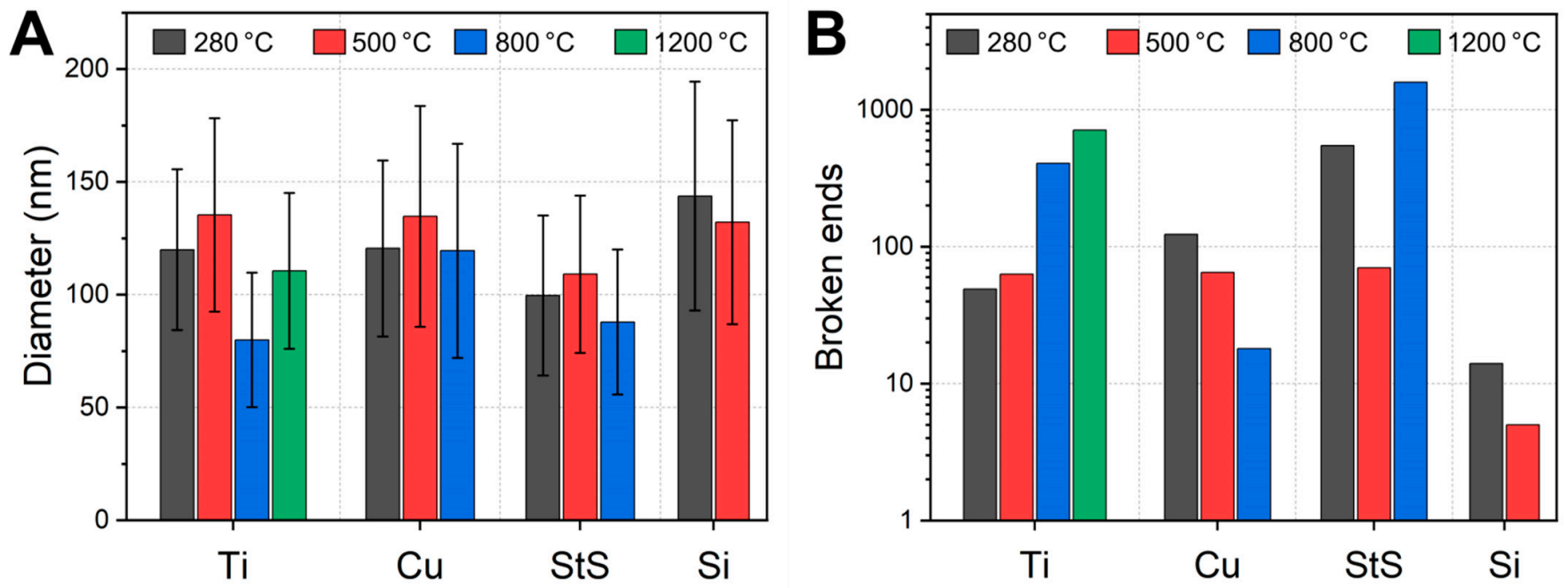

Figure 3. (A) Average nanofiber diameters and (B) numbers of broken nanofiber ends counted in the HIM images with a field of view of $30 \times 30 \mu \mathrm{m}^{2}$, as shown in Figure 2. The y-scale is logarithmic. A temperature of $280^{\circ} \mathrm{C}$ refers to the stabilized samples.

Besides the morphology, the degrees of carbonization and crystallinity are crucial determinants of the mechanical and electrical properties of the CNF obtained. Figure 4 shows Raman spectra in the D band (around $1350 \mathrm{~cm}^{-1}$ ) and G band (around $1580 \mathrm{~cm}^{-1}$ ) regions of the stabilized and carbonized nanofiber mats. While the $\mathrm{G}$ band is related to in-plane bond-stretching motion of pairs of $\mathrm{sp}^{2}$ hybridized carbon atoms the $\mathrm{D}$ band stems from defects in the aromatic ring structure of the graphite lattice or domain boundaries of graphite crystallites $[25,26]$. The ratio $I_{D} / I_{G}$ thus gives the ratio of disordered to ordered graphitic domains, i.e., a measure for crystallinity of the samples, with higher crystallinity being indicated by a lower ratio $I_{D} / I_{G}$ [27]. Interestingly, Figure 5 shows not only increasing crystallinity for increasing carbonization temperature, but also differences between the substrate materials. While the highest crystallinity is reached for carbonization at $1200{ }^{\circ} \mathrm{C}$ using Ti substrates, similar values were also reached at lower temperatures of $800{ }^{\circ} \mathrm{C}$ for the $\mathrm{Cu}$ substrate and even for $500{ }^{\circ} \mathrm{C}$ for the Si substrate. Measuring $I_{D} / I_{G}$ after incipient carbonization at $500{ }^{\circ} \mathrm{C}$ in an aluminum sandwich resulted in a value of approx. 1.2 [23], i.e., a lower crystallinity than found for the materials used in the recent study. It can be concluded that the metal substrate, possibly through catalytic activity in the pyrolysis reaction, has a significant effect on the degree of crystallization of the CNF, which may allow similar results to be obtained at much lower temperature via substrate variation.

To investigate the chemical properties, i.e., the gradual removal of oxygen-functional groups, FTIR spectroscopy was performed. The results are depicted in Figure 5. After stabilization, the curves measured on different substrates are mostly similar. The wellknown peaks occur around $800 \mathrm{~cm}^{-1}$ (aromatic $\mathrm{C}-\mathrm{H}$ ring bending vibrations), $1575 \mathrm{~cm}^{-1}$ ( $\mathrm{C}=\mathrm{N}$ and $\mathrm{C}=\mathrm{C}$ stretching vibrations), $1370 \mathrm{~cm}^{-1}$ (C-H deformation), and $1240 \mathrm{~cm}^{-1}$ (C-O vibrations due to oxygen crosslinking between the polymer chains) $[9,28]$.

Pure carbon shows no peaks at all as it is almost chemically inert [29,30]. As can be seen in Figure 5B, only CNF carbonized on Ti and Si substrates show signs of residual functional groups after carbonization at $500{ }^{\circ} \mathrm{C}$ (the artifact near $2100 \mathrm{~cm}^{-1}$ visible for stainless steel stems from the incompletely compensated strong absorption of the diamond ATR crystal). In particular, CNF carbonized on Ti show pronounced bands between 1700 and $1000 \mathrm{~cm}^{-1}$, which is consistent with the lowest degree of crystallinity, as determined by Raman spectroscopy. Similarly, incipient carbonization at $500{ }^{\circ} \mathrm{C}$ in an aluminum sandwich resulted in nearly completely vanished peaks in the previous study [23]. At higher carbonization temperatures no distinct bands were observed (Figure 5C). 

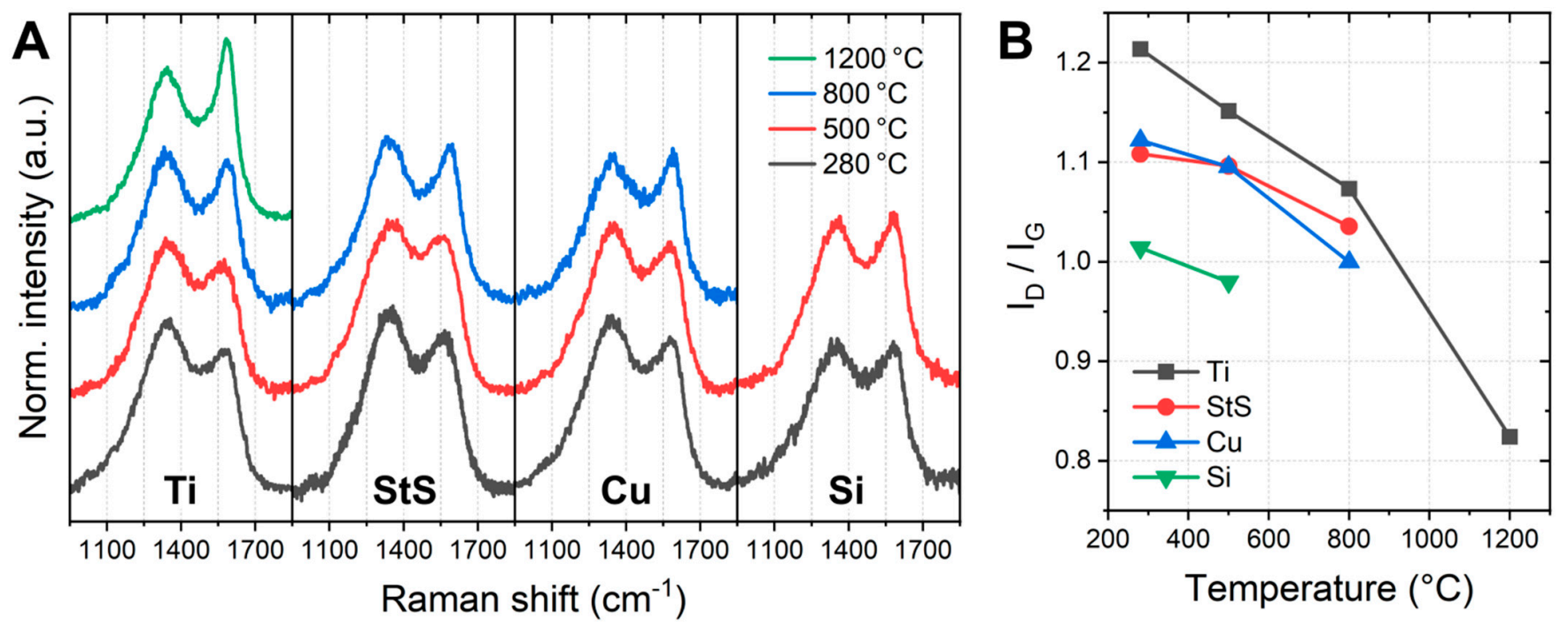

Figure 4. Raman investigations of the stabilized and carbonized nanofibers: (A) D and G band regions and (B) corresponding amplitude ratios $I_{D} / I_{G}$.
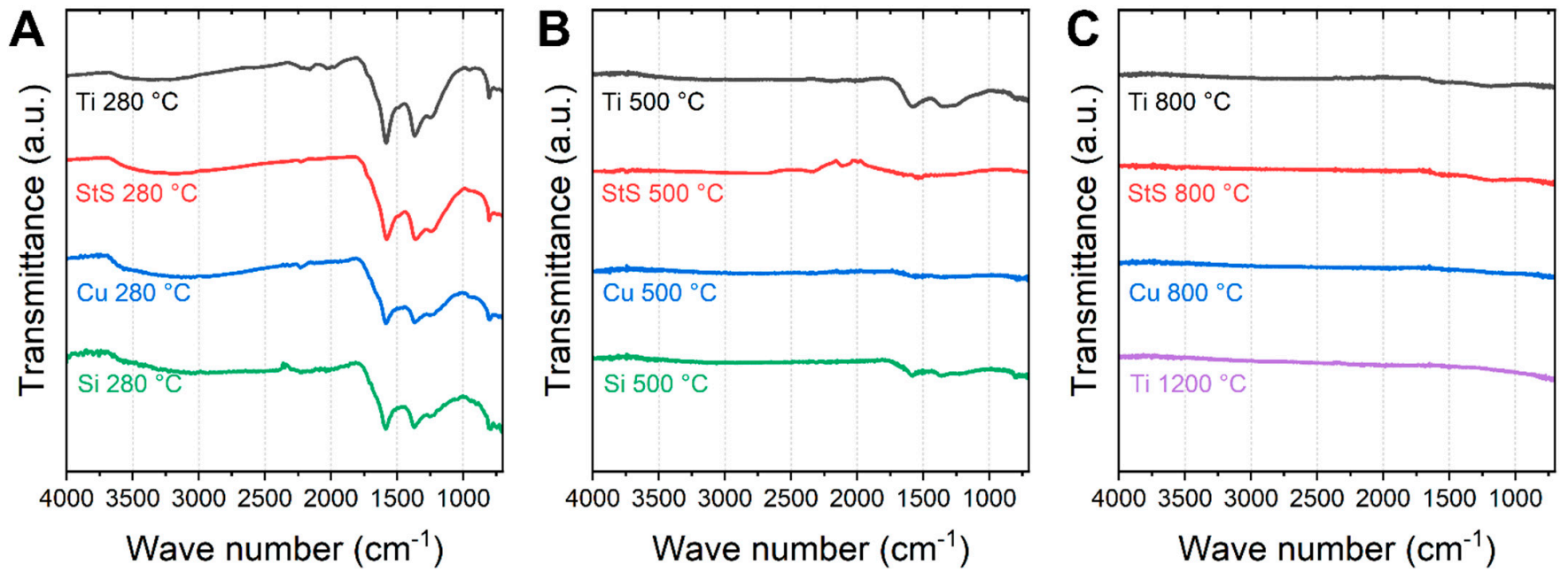

Figure 5. FTIR investigations of the stabilized and carbonized nanofibers: (A) stabilization on different substrates, (B) carbonization at $500{ }^{\circ} \mathrm{C}$, and (C) carbonized at higher temperatures.

It should be mentioned that besides all aforementioned spinning, stabilization and carbonization parameters, the thickness of the specimen has a significant impact on the carbonization results. It has been observed that a higher sample thickness, i.e., spinning duration (cf. Figure 1B), stabilizes the CNF mats against macroscopic deformation and breaking. In this regard a $(3.5 \pm 0.8) \mu \mathrm{m}$ thick nanofiber mat carbonized at $1200{ }^{\circ} \mathrm{C}$ on a Ti substrate had mostly maintained its macroscopic appearance (cf. Figure S1A in the supplementary materials), while a sample with a thickness of $(1.1 \pm 0.4) \mu \mathrm{m}$ had shrunk significantly more (cf. Figure S1B in the supplementary materials). An even thinner specimen with $(0.2 \pm 0.1) \mu \mathrm{m}$ completely folded in on itself and had no resemblance to the pristine nanofiber mat whatsoever. Apparently, a certain minimum thickness is necessary to maintain useful CNF after carbonization under these conditions.

\section{Conclusions}

PAN nanofiber mats were stabilized and subsequently carbonized at $500{ }^{\circ} \mathrm{C}, 800{ }^{\circ} \mathrm{C}$ and $1200{ }^{\circ} \mathrm{C}$, sandwiched between different metal and metalloid substrates. For higher temperatures, a higher degree of carbonization and crystallinity was found. The highest nanofiber integrity was found for the Si substrate after carbonization at $500{ }^{\circ} \mathrm{C}$, which was 
not sufficient to reach a high degree of carbonization, while such nanofibers may be well suitable for producing nano-composites with enhanced mechanical properties, as compared to the pure polymer. The Ti substrate enabled carbonization at $1200{ }^{\circ} \mathrm{C}$, but showed lower degrees of carbonization than the other substrate materials at lower temperatures. While a high crystallinity was only achieved with the Ti substrate after carbonization at $1200^{\circ} \mathrm{C}, \mathrm{Cu}$ and $\mathrm{StS}$ substrates achieved a high degree of carbonization at only $500{ }^{\circ} \mathrm{C}$. Since $\mathrm{CNF}$ from $\mathrm{Cu}$ substrates showed relatively small numbers of broken ends, all in all carbonization in a $\mathrm{Cu}$ sandwich at $800^{\circ} \mathrm{C}$ offers a balanced optimum of carbonization, crystallinity, and intact nanofibers. The improvement of the carbonization process with regard to the resulting crystallinity and morphology is of general significance to any kind of application that has been proposed over recent years. Examples include the use of CNF in energy storage applications with regard to electrochemical properties or the application in composite materials that benefit from improved morphological and mechanical properties.

The results demonstrate that carbonization of PAN nanofibers on metal substrates has significant advantages over conventional methods, not only avoiding undesired nanofiber deformation but also enhancing the resulting CNF in terms of physiochemical properties.

Supplementary Materials: The following supporting information can be downloaded at: https: // www.mdpi.com/article/10.3390/polym14040721/s1, Figure S1: Photographic images of specimens after carbonization in Ti sandwiches at $1200{ }^{\circ} \mathrm{C}$ for $1 \mathrm{~h}$ with different original thicknesses.

Author Contributions: Conceptualization, J.L.S. and T.G.; methodology, J.L.S., C.H. and T.G.; formal analysis, C.H., M.W. and A.E.; investigation, J.L.S., M.W., N.F., B.B., C.H., E.D. and T.G.; writingoriginal draft preparation, M.W. and A.E.; writing - review and editing, all authors; visualization, M.W. and A.E. All authors have read and agreed to the published version of the manuscript.

Funding: This research was funded by the German Federal Ministry for Economic Affairs and Energy (grant no. 03THW09K08) and by the German Federal Ministry of Education and Research, funding program Forschung an Fachhochschulen (grant no. 13FH018AN9).

Institutional Review Board Statement: Not applicable.

Informed Consent Statement: Not applicable.

Data Availability Statement: All data produced in this study are presented in this paper.

Acknowledgments: We are grateful to Armin Gölzhäuser from Bielefeld University for providing the opportunity to use the helium ion microscope.

Conflicts of Interest: The authors declare no conflict of interest. The funders had no role in the design of the study; in the collection, analyses, or interpretation of data; in the writing of the manuscript; or in the decision to publish the results.

\section{References}

1. Rahaman, M.S.A.; Ismail, A.F.; Mustafa, A. A review of heat treatment on polyacrylonitrile fiber. Polym. Degrad. Stab. 2007, 92, 1421-1432. [CrossRef]

2. Sabantina, L.; Klöcker, M.; Wortmann, M.; Rodríguez-Mirasol, J.; Cordero, T.; Moritzer, E.; Finsterbusch, K.; Ehrmann, A. Stabilization of PAN nanofiber mats obtained by needleless electrospinning using DMSO as solvent. J. Ind. Text. 2020, 50, 224-239. [CrossRef]

3. Manoharan, M.P.; Sharma, A.; Desai, A.V.; Haque, M.A.; Bakis, C.E.; Wang, K.W. The interfacial strength of carbon nanofiber epoxy composite using single fiber pullout experiments. Nanotechnology 2009, 20, 295701. [CrossRef]

4. Wang, J.; Park, Y.K.; Jo, Y.M. Sequential improvement of activated carbon fiber properties for enhanced removal efficiency of indoor $\mathrm{CO}_{2}$. J. Ind. Eng. Chem. 2020, 89, 400-408. [CrossRef]

5. Dirican, M.; Yanilmaz, M.; Asiri, A.M.; Zhang, X.W. Polyaniline $/ \mathrm{MnO}_{2} /$ porous carbon nanofiber electrodes for supercapacitors. J. Electroanal. Chem. 2020, 861, 113995. [CrossRef]

6. Abdullah, N.; Othman, F.E.C.; Yusof, N.; Matsuura, T.; Lau, W.J.; Jaafar, J.; Ismail, A.F.; Salleh, W.N.W.; Aziz, F. Preparation of nanocomposite activated carbon nanofiber/manganese oxide and its adsorptive performance toward leads (II) from aqueous solution. J. Water Process. Eng. 2020, 37, 101430. [CrossRef] 
7. Meligrana, G.; Ferrari, S.; Lucherini, L.; Celè, J.; Colò, F.; Brugger, J.; Ricciardi, C.; Ruffo, R.; Gerbaldi, C. $\mathrm{Na}_{3} \mathrm{~V}_{2}\left(\mathrm{PO}_{4}\right)_{3}-\mathrm{Supported}$ Electrospun Carbon Nanofiber Nonwoven Fabric as Self-Standing Na-Ion Cell Cathode. ChemElectroChem 2020, 7, 1652-1659. [CrossRef]

8. Banitaba, S.N.; Ehrmann, A. Application of electrospun nanofibers for fabrication of versatile and highly efficient electrochemical devices: A review. Polymers 2021, 13, 1741. [CrossRef]

9. Mólnar, K.; Szolnoki, B.; Toldy, A.; Vas, L.M. Thermochemical stabilization and analysis of continuously electrospun nanofibers. J. Anal. Calorim. 2014, 117, 1123-1135. [CrossRef]

10. Arbab, S.; Teimoury, A.; Mirbaha, H.; Adolphe, D.C.; Noroozi, B.; Nourpanah, P. Optimum stabilization processing parameters for polyacrylonitrile-based carbon nanofibers and their difference with carbon (micro) fibers. Polym. Degrad. Stab. 2017, 142, 198-208. [CrossRef]

11. Hu, G.F.; Zhang, X.H.; Liu, X.Y.; Yu, J.Y.; Ding, B. Strategies in precursors and post treatments to strengthen carbon nanofibers. Adv. Fiber Mater. 2020, 2, 46-63. [CrossRef]

12. Bashir, Z. A critical review of the stabilisation of polyacrylonitrile. Carbon 1991, 29, 1081-1090. [CrossRef]

13. Ismar, E.; Sezai, S.A. Oxidation of polyacrylonitrile nanofiber webs as a precursor for carbon nanofiber: Aligned and non-aligned nanofibers. Polym. Bull. 2017, 75, 485-499. [CrossRef]

14. Dhakate, S.R.; Gupta, A.; Chaudhari, A.; Tawale, J.; Mathur, R.B. Morphology and thermal properties of PAN copolymer based electrospun nanofibers. Synth. Met. 2011, 161, 411-419. [CrossRef]

15. Alarifi, I.M.; Alharbi, A.; Khan, W.S.; Swindle, A.; Asmatulu, R. Thermal, Electrical and Surface Hydrophobic Properties of Electrospun Polyacrylonitrile Nanofibers for Structural Health Monitoring. Materials 2015, 8, 7017-7031. [CrossRef]

16. Wortmann, M.; Frese, N.; Mamun, A.; Trabelsi, M.; Keil, W.; Büker, B.; Javed, A.; Tiemann, M.; Moritzer, E.; Ehrmann, A.; et al Chemical and Morphological Transition of Poly(acrylonitrile)/Poly(vinylidene Fluoride) Blend Nanofibers during Oxidative Stabilization and Incipient Carbonization. Nanomaterials 2020, 10, 1210. [CrossRef]

17. Wu, M.; Wang, Q.Y.; Li, K.; Wu, Y.Q.; Liu, H.Q. Optimization of stabilization conditions for electrospun polyacrylonitrile nanofibers. Polym. Degrad. Stab. 2012, 97, 1511-1519. [CrossRef]

18. Ma, S.; Liu, J.; Liu, Q.; Liang, J.Y.; Zhao, Y.; Fong, H. Investigation of structural conversion and size effect from stretched bundle of electrospun polyacrylonitrile copolymer nanofibers during oxidative stabilization. Mater. Des. 2016, 95, 387-397. [CrossRef]

19. Santos de Oliveira, M., Jr.; Manzolli Rodrigues, B.V.; Marcuzzo, J.S.; Guerrini, L.M.; Baldan, M.R.; Rezende, M.C. A statistical approach to evaluate the oxidative process of electrospun polyacrylonitrile ultrathin fibers. J. Appl. Polym. Sci. 2017, 134, 45458. [CrossRef]

20. Sabantina, L.; Rodríguez-Cano, M.Á.; Klöcker, M.; García-Mateos, F.J.; Ternero-Hidalgo, J.J.; Mamun, A.; Beermann, F.; Schwakenberg, M.; Voigt, A.-L.; Rodríguez-Mirasol, J.; et al. Fixing PAN nanofiber mats during stabilization for carbonization and creating novel metal/carbon composites. Polymers 2018, 10, 735. [CrossRef]

21. Storck, J.L.; Grothe, T.; Tuvshinbayar, K.; Diestelhorst, E.; Wehlage, D.; Brockhagen, B.; Wortmann, M.; Frese, N.; Ehrmann, A. Stabilization and incipient carbonization of electrospun polyacrylonitrile nanofibers fixated on aluminum substrates. Fibers 2020, 8, 55. [CrossRef]

22. Storck, J.L.; Brockhagen, B.; Grothe, T.; Sabantina, L.; Kaltschmidt, B.; Tuvshinbayar, K.; Braun, L.; Tanzli, E.; Hütten, A.; Ehrmann, A. Stabilization and carbonization of PAN nanofiber mats electrospun on metal substrates. C J. Carbon Res. 2021, 7, 12. [CrossRef]

23. Storck, J.L.; Hellert, C.; Brockhagen, B.; Wortmann, M.; Diestelhorst, E.; Frese, N.; Grothe, T.; Ehrmann, A. Metallic supports accelerate carbonization and improve morphological stability of polyacrylonitrile nanofibers during heat treatment. Materials 2021, 14, 4686. [CrossRef] [PubMed]

24. Wortmann, M.; Layland, A.S.; Frese, N.; Kahmann, U.; Grothe, T.; Storck, J.L.; Blachowicz, T.; Grzybowski, J.; Hüsgen, B.; Ehrmann, A. On the reliability of highly magnified micrographs for structural analysis in materials science. Sci. Rep. 2020, 10, 14708. [CrossRef]

25. Hodkiewicz, J. Characterizing Carbon Materials with Raman Spectroscopy; Application Note 51901; Thermo Fisher Scientific: Madison, WI, USA, 2010.

26. Ferrari, A.C.; Meyer, J.C.; Scardaci, V.; Casiraghi, C.; Lazzeri, M.; Mauri, F.; Piscanec, S.; Jiang, D.; Novoselov, K.S.; Roth, S.; et al. Raman Spectrum of Graphene and Graphene Layers. Phys. Rev. Lett. 2006, 97, 187491. [CrossRef]

27. Wortmann, M.; Keil, W.; Brockhagen, B.; Biedinger, J.; Westphal, M.; Weinberger, C.; Diestelhorst, E.; Hachmann, W.; Zhao, Y.; Tiemann, M.; et al. Pyrolysis of sucrose-derived hydrochar. J. Anal. Appl. Pyrolysis 2022, 161, 105404. [CrossRef]

28. Gergin, I.; Ismar, E.; Sarac, A.S. Oxidative stabilization of polyacrylonitrile nanofibers and carbon nanofibers containing graphene oxide (GO): A spectroscopic and electrochemical study. Beilstein J. Nanotechnol. 2017, 8, 1616-1628. [CrossRef]

29. Arshad, S.N.; Naraghi, M.; Chasiotis, I. Strong carbon nanofibers from electrospun polyacrylonitrile. Carbon 2011, 49, 1710-1719. [CrossRef]

30. Park, C.-W.; Youe, W.-J.; Han, S.-Y.; Kim, Y.S.; Lee, S.-H. Characteristics of carbon nanofibers produced from lignin/polyacrylonitrile (PAN)/kraft lignin-g-PAN copolymer blends electrospun nanofibers. Holzforschung 2017, 71, 743-750. [CrossRef] 